\title{
Understanding Conditions in Income Transfer Programmes: A Brief(est) Note
}

\author{
Armando Barrientos*
}

\begin{abstract}
'Are people in poverty more or less like you and me but with less money?' There is a sense in which the correct answer to this question is 'Yes'. People in poverty have not dropped in from Venus or Mars; they are not an altogether different species to people who are not in poverty. In all probability, measured by studies distinguishing between chronic and transient poverty, some of those who are not currently in poverty will fall into poverty at some stage in their lives.
\end{abstract}

However, as a description of what being in poverty is, or of the reasons why people fall into poverty, the correct answer must be an unqualified ' $N o$ '. In most cases, and especially in developing countries, being in poverty describes a range of deficits or deprivations, including insufficient consumption, lack of access to basic services, limited opportunities for economic activity, political disenfranchisement, and gender or age discrimination, to name but a few. In many cases, being in poverty persists for considerable periods of time, even across lifetimes and generations.

There is growing recognition that poverty is multidimensional and can persist in time, and that, as a consequence, anti-poverty policy must address the range of deficits that draw households into poverty and can keep them there. This is apparent from a large and growing literature and practice on emerging new forms of social assistance in developing countries, including categorical income transfers, conditional and unconditional income transfers, reformed social safety net programmes and poverty reduction strategies. It is tremendously encouraging that this understanding of poverty is having a direct influence on policy, in the design and implementation of integrated anti-poverty programmes. These combine a range of interventions, such as the conditional cash transfer programmes in Latin America, which link income transfers to support consumption with health, schooling and nutrition interventions, or the integrated programmes directed at the extreme poor such as Chile's Chile Solidario, or Bangladesh's Challenging the Frontiers of Poverty Reduction: Targeting the Ultra-poor Programme.

A common factor in these anti-poverty programmes is the use of cash or income transfers, as an essential element. They provide a regular and reliable injection of purchasing power, enabling the kind of investment in nutrition, healthcare and schooling which could lead to a sustained escape from poverty in the long term. They are not, however, the sole element in the programme. Linkages to basic services, as in the case of the Latin American programme mentioned above, or income-generating activities, as in the Bangladesh programme, are significant elements. These linkages to other key interventions expand as the programmes develop, as has been the experience of Mexico's Oportunidades. The quality of these linkages varies from programme to programme. Brazil's Bolsa Familia and Mexico's Oportunidades, for example, include a conditionality that children of school-going age attend school regularly, but rely on the relevant Ministry to ensure that school places are available. Coordination at the local level is important. Other conditional cash transfer programmes, such as Honduras' PRAF II and Nicaragua's Red de Protección Social have similar conditionalities but include direct transfers to schools to support additional places for programme beneficiaries. 
It is important to note, before conditionalities are discussed, that there are many other features of income transfer programmes that are covered in the literature, including whether the programmes reach those in poverty and those in greatest poverty; whether the forms of assistance provided are effective and adequate to ensure a significant reduction in poverty; whether the programmes are likely to strengthen, or help establish, broader social protection systems; whether the programmes support the emergence of a 'social contract' to underpin social protection; and issues of financial and implementation capacity. There is also the importance of context in arriving at conclusions on these issues that are capable of informing policy.

It would be hard to make a case that the issue of conditionality can compete in significance with those listed above. However, understanding the role of conditionalities in income transfer programmes addressing poverty could help to clarify this.

There are different rationales for the inclusion of conditionalities in income transfer programmes. First, conditionalities could be included to achieve programme objectives. Work requirements for income transfers, as in public works programmes, are commonly introduced to facilitate the objective of reaching those unable to secure employment. Requiring beneficiaries to supply a certain amount of work, and setting the benefit at a level below the local market wage, excludes those who could secure employment outside the programme. Where conditional cash transfer programmes are aimed at securing household investment in schooling or healthcare, the transfer could be made conditional on children attending school on a regular basis, or on regular access to primary healthcare. Conditionalities help to ensure these programme objectives.

Second, conditionalities may reflect the concerns of tax-payers that potential beneficiaries take full advantage of the transfers. Alternative explanations for the tax-payers' concerns are possible: paternalistic tax-payers may wish to impose on beneficiaries the values and priorities they themselves hold; prudent tax-payers may be concerned to ensure that beneficiaries exit poverty thereby limiting future liabilities; self-interested tax-payers may be keen to prevent behaviour with adverse effects for themselves - for example requiring children to be at school means they will not be loitering in the streets.
Third, conditionalities may be included to facilitate political support for the income transfer programmes by signalling a commitment to deliver on its objectives. It is also possible for conditionalities to respond to a combination of the above.

In Latin America, the primary factor behind the adoption of conditionalities has been the need to achieve the programme objectives of ensuring household investment in human capital. These are deemed essential to help break the intergenerational cycle of poverty. Research has indicated that schooling and healthcare utilisation are deficient for many of those in poverty, and especially those in extreme poverty, even where these services are available. This is because people in poverty face high costs, relative to their resources, of accessing these services, and because of exclusion. Income transfers are intended to help remove the cost barrier, while programme linkages to service providers are expected to help lower exclusion. Conditionalities that are meant to ensure household investment in schooling and healthcare can also ensure a measure of coordination between programme managers and service providers. This is the theory; practice is another thing altogether.

Some argue that conditionalities are unnecessary, in that programme objectives could be achieved without them. Others criticise the use of conditionalities in income transfer programmes in certain circumstances. There is sense and no-sense in both these views.

Some argue that conditionalities relating to health and education are unnecessary because people in poverty would have sent their children to school, or made use of primary healthcare, in the absence of conditionalities. But it is important to pay attention to the marginal beneficiaries. In rural Mexico, dropout rates at the start of secondary school, especially for girls, were unacceptably high. Estimates of the impact of Oportunidades on enrolment rates suggest that two years after the start of the programme, these had increased by around 1 percentage point (from a base of 90-94 per cent) for boys in primary school and as much as 9.3 percentage points (from a base of 67 per cent) for girls in secondary school. The impact of the conditionality is measured by the marginal households that enrolled their children, or did not withdraw them as they would otherwise have done. Whether this is worth the 2 per cent of transfer costs absorbed by implementing conditionalities in Oportunidades is a separate issue (Caldès et al. 2004). 
Some argue that conditionalities are unnecessary because unconditional transfers also show a positive impact on enrolment rates, for example the social pension in South Africa. This is fine up to a point. We need to know more about the size of these effects, and why they appear to be gendered, that is why girls' enrolments rise with female pensioners, but boys' enrolments do not (Duflo 2003). Estimates of the impact of income transfers are hard to identify with precision because of the absence of counterfactuals, i.e. what would have happened if the programme had not been there. There are few valid counterfactuals to identify the impact of conditionalities, but it would be hard to argue that they are either never, or always, necessary.

Some argue that conditionalities will not work under certain conditions, and this is true as far as it goes. Schooling conditionalities are unlikely to work where it is not possible to expand school places, but if the objective of the programme is to increase enrolments and school attendance, then unconditional income transfers will not work either. The issue here is to combine income transfers with improvements in school infrastructure, independently of whether transfers are conditional or unconditional. Similar arguments apply to health services.

The main problem with introducing conditionalities in income transfers arises when these impose compliance costs on those in poverty. These include time spent by mothers ensuring that conditions are met, filling forms, and queuing at schools or clinics. To the extent that these are non-trivial and are not accounted for in setting the level of the transfer, they are likely to compound the adverse situation of those in poverty. Conditional income transfer programmes seldom collect information on

\section{Note}

* Given space limitations, I have 'economised' on references. Readers interested in more should contact me at a.barrientos@ids.ac.uk.

\section{References}

Caldès, N., Coady, D. and Maluccio, J.A. (2004) The Cost of Poverty Alleviation Transfer Programs: A Comparative Analysis of Three Programs in Latin America, Discussion Paper 174, Washington DC: International Food Policy Research Institute (IFPRI) compliance costs for beneficiaries, or attempt to account for these in setting benefits.

What about ethical concerns with conditionalities? All public policy involves important and contentious ethical issues, and those associated with income transfers need to be treated with care. This would require a more extensive treatment than the space at my disposal permits. I shall restrict myself to making a non-controversial point. Many countries have legislation requiring compulsory schooling at primary, and increasingly at secondary school level. Most countries have legislation restricting child labour and many countries have early childhood interventions which include immunisation of infants. To the extent that conditionalities apply to these areas, similar ethical issues arise.

To conclude, people in poverty have deficits which extend beyond purchasing power and which may cause the persistence of poverty. It is encouraging that this perspective on poverty is exerting a strong influence on new forms of social assistance. Among these, conditional income transfers require beneficiaries to invest in schooling, healthcare and nutrition. As with other design features of income transfers, conditionalities reflect programme objectives, social preferences and political factors, and conditionalities have advantages and limitations, and are contextspecific. A concern with conditionalities is the extent to which they impose non-trivial compliance costs on beneficiaries that are not accounted for in setting benefit levels. Conditionalities can strengthen linkages between income transfers and access to basic services. They are likely to be effective, if at all, at the margins. An understanding of the role of conditionalities in income transfers, hastily undertaken in this brief note, helps to put these in perspective.
Duflo, E. (2003) 'Grandmothers and Granddaughters: Old Age Pensions and Intrahousehold Allocation in South Africa', World Bank Economic Review 17.1: $1-25$ 